\title{
Use of a homemade endoscopic guillotine to cut through a nasogastric tube inadvertently sutured to a colon-gastric anastomosis
}
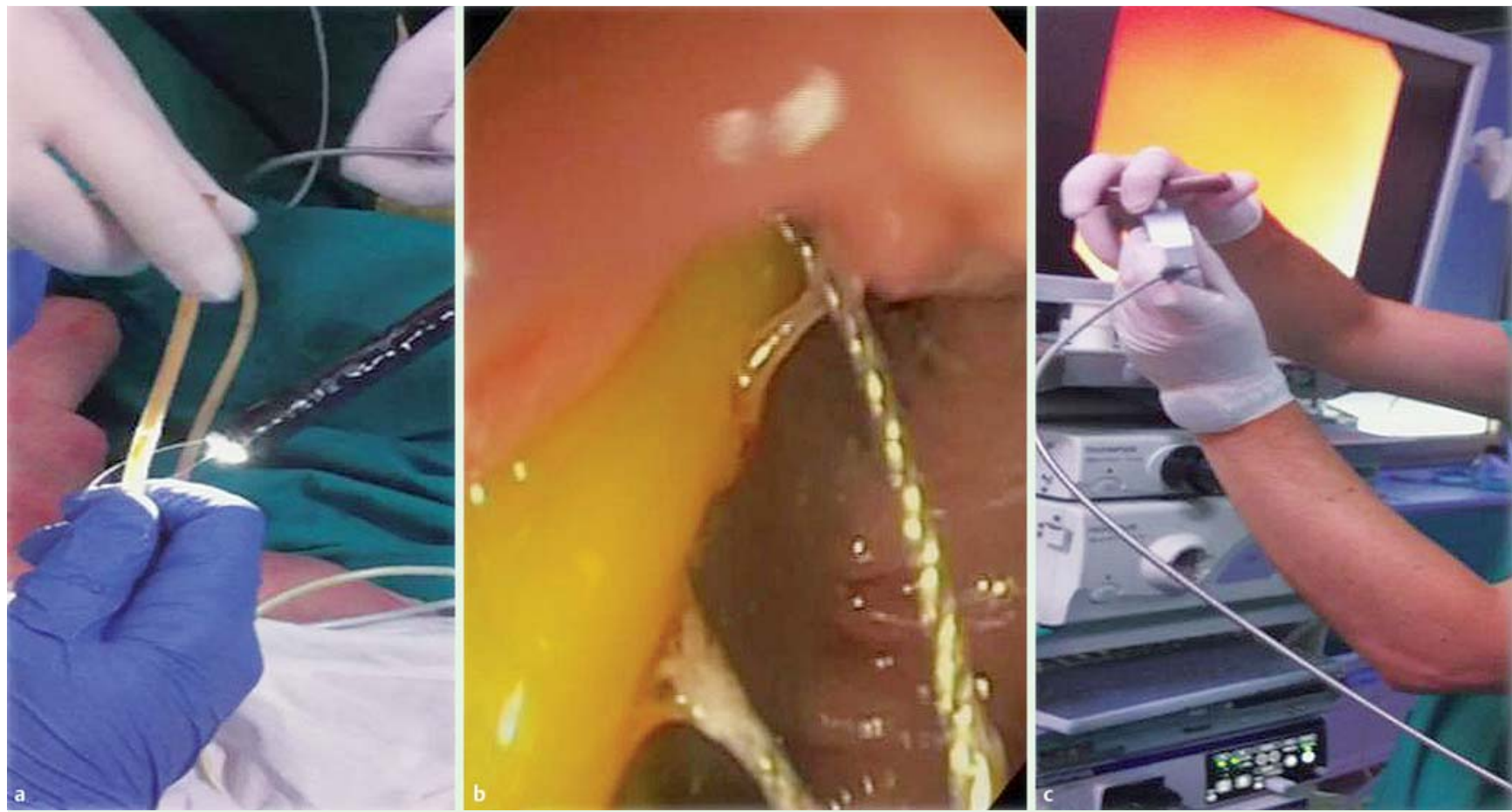

Fig. 1 Use of a homemade endoscopic guillotine to cut through an inadvertently sutured nasogastric tube (NGT). a The NGT, which has been brought out through the patient's mouth, is looped with the snare. $\mathbf{b}$ The NGT is used as a guide for the endoscope until the desired point for cutting of the NGT is reached. c The crank handle is rotated to cut through the NGT once the loop of the snare is in the desired position.

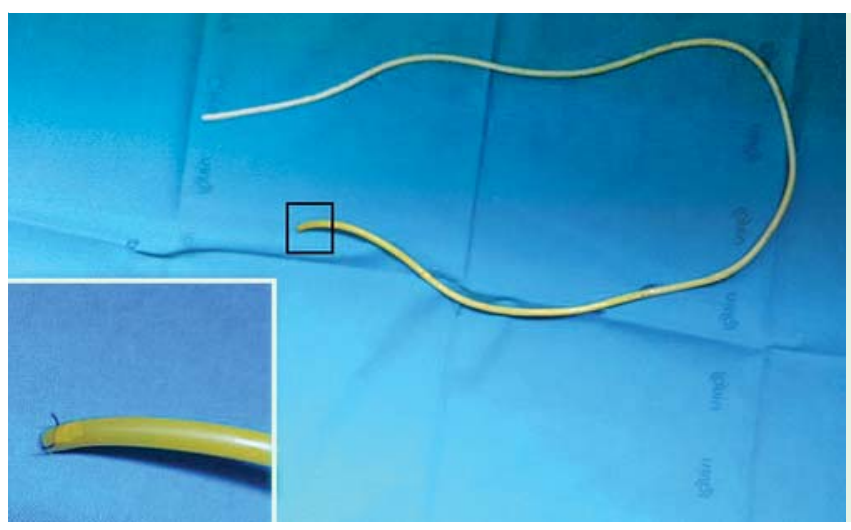

Fig. 2 The truncated nasogastric tube following removal, with the cut stitch visible at its distal end (inset).

Suturing a nasogastric tube (NGT) while creating a surgical anastomosis is a rare complication. Once this has occurred however endoscopic removal of the NGT for the patient's relief can be very challenging.

A 41-year-old man who had previously undergone esophago-colon-gastroplasty because of a congenital esophageal stricture underwent further surgery on the proximal colon-gastric anastomosis gesting that the NGT had been inadvertently sutured into the CGA.

A homemade device in the form of an endoscopic guillotine, previously described as being successful in trimming plastic biliary stents [1], was used to cut the NGT. The endoscopic guillotine is made by combining the metal sheath from a mechanical lithotriptor (Innoflex IGL $1957 \mathrm{M}, 7 \mathrm{Fr}, 165 \mathrm{~cm}$ ) and a polypectomy snare (Olympus SD-210U-15, loop diameter $15 \mathrm{~mm}, 230 \mathrm{~cm}$ ) from which the outer plastic sheath has been stripped and the handle removed. The snare is inserted into the metal sheath and connected to the crank, in the same way as a Dormia basket is usually loaded for lithotripsy.

First the end of the NGT was brought out through the mouth of the patient. It was then looped with the snare ( $\bullet$ Fig. 1 a) and used as a guide for the endoscope until the desired point for the NGT to be cut through, close to the CGA, was reached ( Fig. 1 b). Once the loop was in the desired position, the crank handle of the lithotriptor was gradually turned $(\bullet$ Fig. $1 \mathrm{c})$ 


\section{Video 1}

The nasogastric tube (NGT) is looped within the snare and used as a guide until the desired point for cutting through the NGT is reached. The crank handle of the lithotriptor is turned until the NGT has been cut through. The truncated NGT is then easily retrieved, revealing a stitch that has also been cut through at its distal end.

until the NGT had been completely severed ( Video 1). The truncated NGT was then easily retrieved. Surprisingly, when it was examined a Vicryl stitch that had also been cut off was found close to the cut end ( $\bullet$ Fig.2). The distal part of the NGT was left in place and subsequently migrated spontaneously.
Endoscopy_UCTN_Code_TTT_1AO_2AK

Competing interests: None

\section{Domenico Galasso, Andrea Tringali, Maria Elena Riccioni, Guido Costa- magna}

Digestive Endoscopy Unit, A. Gemelli Hospital, Rome, Italy

\section{References}

1 Mutignani M, Dokas S, Perri V et al. Post-insertion tailoring of plastic biliary stents: A novel technique. Endoscopy 2006; 38: 856
Bibliography

Dol http://dx.doi.org/

10.1055/s-0033-1358812

Endoscopy 2013; 45: E413-E414

(c) Georg Thieme Verlag KG

Stuttgart · New York

ISSN 0013-726X

Corresponding author

Domenico Galasso, MD

Digestive Endoscopy Unit

"A. Gemelli" Hospital

Largo A. Gemelli 8

Rome 00168

Italy

Fax: +39-06-30156581

domenicogalass0512@yahoo.it 